\title{
Country mapping: Nigeria
}

Salisu Mohammed Ishaku

Population Council

Saumya RamaRao

Population Council

Follow this and additional works at: https://knowledgecommons.popcouncil.org/departments_sbsr-rh

Part of the Demography, Population, and Ecology Commons, Family, Life Course, and Society Commons, International Public Health Commons, Maternal and Child Health Commons, Obstetrics and Gynecology Commons, and the Women's Health Commons How does access to this work benefit you? Let us know!

\section{Recommended Citation}

Ishaku, Salisu Mohammed and Saumya RamaRao. 2012. "Country mapping: Nigeria," Progesterone Vaginal Ring Technical Report. New York: Population Council. 

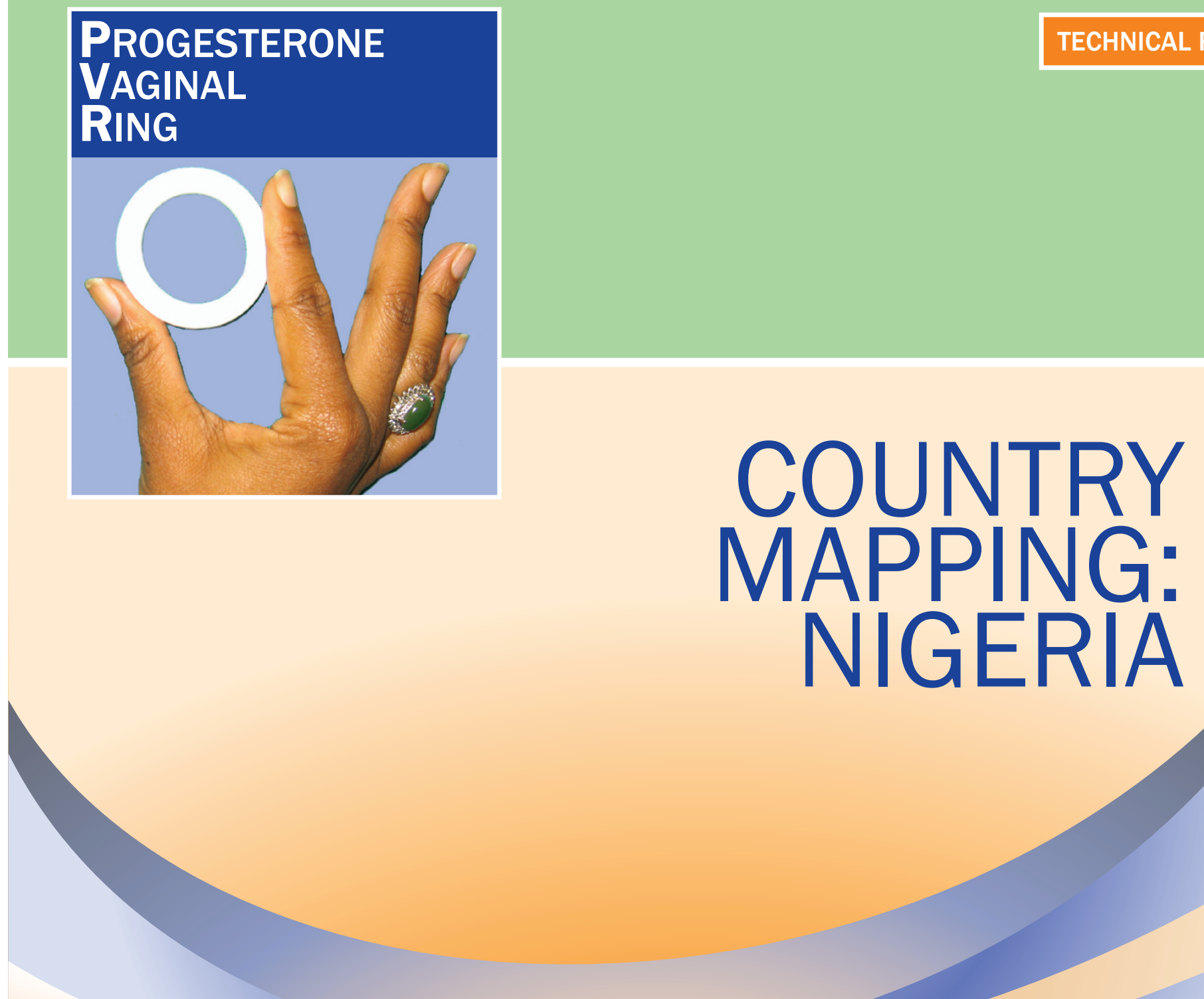

SALISU ISHAKU

SAUMYA RAMARAO

DECEMBER 2012

1P Population Council 


\section{Population Council}

The Population Council confronts critical health and development issues-from stopping the spread of HIV to improving reproductive health and ensuring that young people lead full and productive lives. Through biomedical, social science, and public health research in 50 countries, we work with our partners to deliver solutions that lead to more effective policies, programmes, and technologies that improve lives around the world. Established in 1952 and headquartered in New York, the Council is a nongovernmental, nonprofit organization governed by an international board of trustees.

Population Council

One Dag Hammarskjold Plaza

New York, NY 10017

www.popcouncil.org

\section{Acknowledgments}

This material is for a research project funded by the Bill \& Melinda Gates Foundation. The information contained within does not necessarily reflect positions or policies of the Bill \& Melinda Gates Foundation.

(c) 2012 The Population Council, Inc. 


\section{TABLE OF CONTENTS}

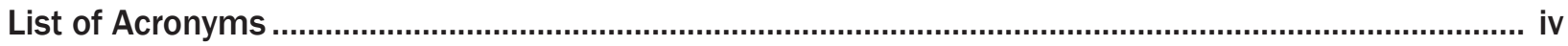

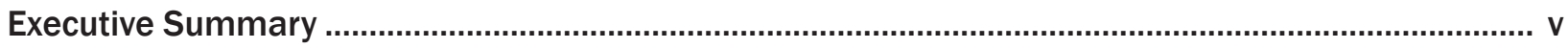

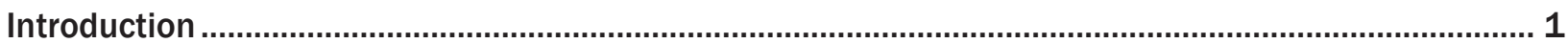

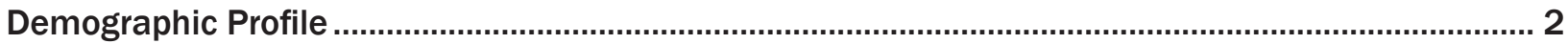

Childbearing and Contraceptive Behavior …................................................................................... 3

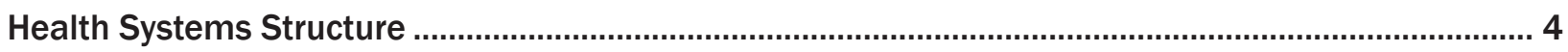

Family Planning and Reproductive Health Policy Context ................................................................ 5

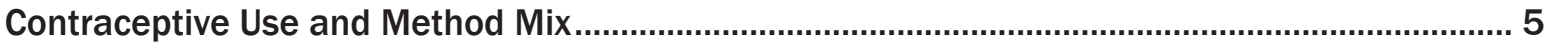

Previous Experiences of Contraceptive Introduction in Nigeria .................................................. 6

Breastfeeding Policies and Practices............................................................................................... 7

Securing Contraceptive Commodities and Getting Them to Market.................................................8

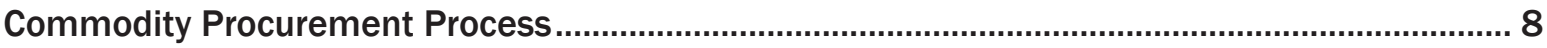

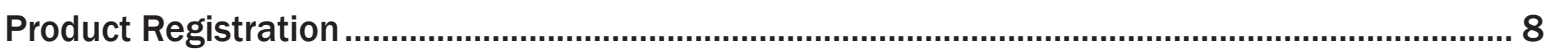

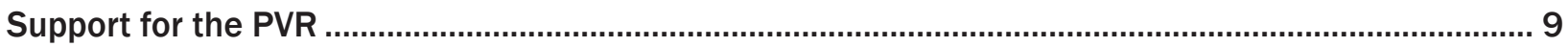

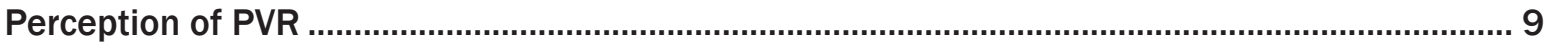

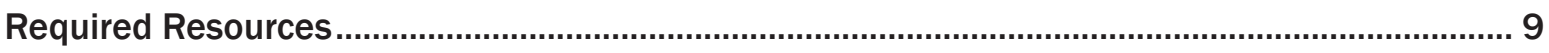

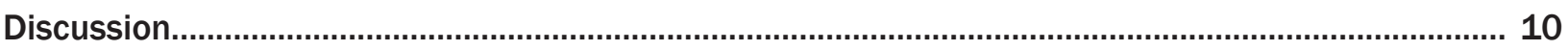

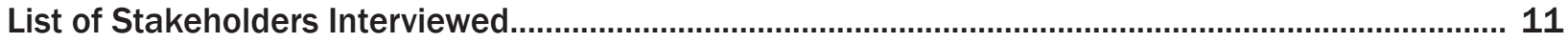

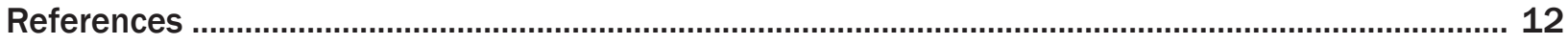




\section{ACRONYMS}

\begin{tabular}{|c|c|c|c|}
\hline ARFH & $\begin{array}{l}\text { Association for Reproductive and Family } \\
\text { Health }\end{array}$ & $\begin{array}{l}\text { NIMR } \\
\mathrm{PHC}\end{array}$ & $\begin{array}{l}\text { National Institute for Medical Research } \\
\text { Primary Health Care }\end{array}$ \\
\hline CLMS & $\begin{array}{l}\text { Contraceptive Logistic Management } \\
\text { Section }\end{array}$ & PPFN & $\begin{array}{l}\text { Planned Parenthood Federation of } \\
\text { Nigeria }\end{array}$ \\
\hline CPR & Contraceptive Prevalence Rate & PVR & Progesterone Vaginal Ring \\
\hline DHS & Demographic and Health Survey & РMTCT & Prevention of Mother-to-Child \\
\hline DfID & UK Department for International & & Transmission \\
\hline & Development & RIF & Requisition Issue Forms \\
\hline $\mathrm{FMoH}$ & Federal Ministry of Health & RIRF & Requisition, Issue, and Report Forms \\
\hline FP & Family Planning & SOPS & Standard Operating Procedures \\
\hline ICA & International Contraceptive Access & SPARHCS & "Strategic Pathway to Reproductive \\
\hline IUCD & Intrauterine Contraceptive Device & & Health Commodity Security" \\
\hline LAM & Lactational Amenorrhea Method & UNFPA & United Nations Population Fund \\
\hline LNG IUS & Levonorgestrel Intra-Uterine System & USAID & $\begin{array}{l}\text { United States Agency for International } \\
\text { Development }\end{array}$ \\
\hline
\end{tabular}


Since 1999, the contraceptive prevalence rate (CPR) for modern methods in Nigeria has stalled at 8-10\%. Maternal, neonatal and child health indices remain abysmally low with maternal and infant mortality ratios of $545 / 100,000$ and $89 / 1,000$ live births respectively. This is a result of multiple contributing factors such as lack of availability and access to long-acting contraceptive commodities, as well as a dearth of skilled service providers that can provide a wide range of methods to satisfy every woman's needs. Currently, attention is being given to increased funding and commitment for family planning and reproductive health services, including the deployment of new technologies in developing countries, to mitigate the problem of unmet need for contraception and to improve maternal and child health. In line with this trend, the Council is conducting a three-year acceptability study of the progesterone vaginal ring (PVR) in three sub-Saharan African Countries-Nigeria, Senegal, and Kenya. The Council research teams conducted assessments to map out the current family planning programs and contraceptive technologies landscape to identify national priorities, evaluate stakeholder interest in the PVR, and devise appropriate pre-introductory activities.

In Nigeria, the research team utilized three approaches to develop this country-specific report: review of available data; desk review of documents, project reports and policy guidelines; and key informant interviews. The interviews were held with government officials, regulatory and development agencies, social marketing organizations, research institutions, advocacy groups, manufacturers and distributors, policymakers, and other members of the community.

This report lays out Nigeria's demographics and high fertility rates, describes the family planning program and policy context, and finally, reveals the stakeholder support thus far with a discussion on how best to proceed with introduction activities.

This country mapping confirms the likelihood that the PVR would be well received in Nigeria and fill a large need in family planning. The PVR is a safe, long-acting, user-controlled product that can be easily inserted and removed by the woman herself with minimal coaching; this is especially appropriate for women in the North who frequent healthcare facilities sparingly due to an aversion to male healthcare providers, need for permission from male partners to visit health facilities, poverty, and a lack of skilled health personnel. The quick return to fertility after discontinuation of use makes the PVR a promising prospect for expanding contraceptive choice for women in Nigeria. All of these characteristics make the PVR a highly desirable addition to the current contraceptive method mix in Nigeria. 


\section{INTRODUCTION}

While the progress made in recent decades in fertility reduction has been impressive, up to 222 million women in the developing world still report an unmet need for contraception (Singh and Darroch 2013). Part of the challenge in addressing current levels of unmet need is the limited use of contraception by women during the first six to 12 months postpartum and the discontinuation rates, with about half of all users abandoning their methods six months after adoption. Both issues lead to limited success in effective birth spacing, which then impacts maternal and infant health. New methods are needed that offer greater ease of use, are womencontrolled, and do not require significant health infrastructure or medical provider involvement for service delivery. One such method is the progesterone vaginal ring (PVR), a user-controlled, mid-acting contraceptive that, according to clinical trial data, is safe and effective for breastfeeding women.

The Population Council has embarked on a threeyear project to explore the acceptability of the PVR among women, their partners, and providers in sub-Saharan Africa and to develop a strategy for its introduction. From February to May 2012 assessments were undertaken in Kenya, Nigeria, and Senegal-potential countries for PVR introduction-to map the landscape of family planning programs and new contraceptive technologies to identify national priorities, and to assess the level of interest in the product among stakeholders and to design appropriate pre-introductory activities. The Council's research teams in each of these countries employed three approaches to develop country-specific reports: a review of Demographic and Health Survey (DHS) data; a desk review of documents, project reports and policy guidelines; and key informant interviews. Interviews were held with representatives of government, regulatory, and development agencies; social marketing organizations; research institutions; manufacturers/distributors; the community; advocacy groups; public/private partnerships; other organizations providing family planning services; and policymakers. This report presents the findings from Nigeria and begins by describing the country demographic profile and unmet need for contraception. It then provides the family planning program and policy context, and concludes with the stakeholder support known thus far and a discussion for what this means moving forward.

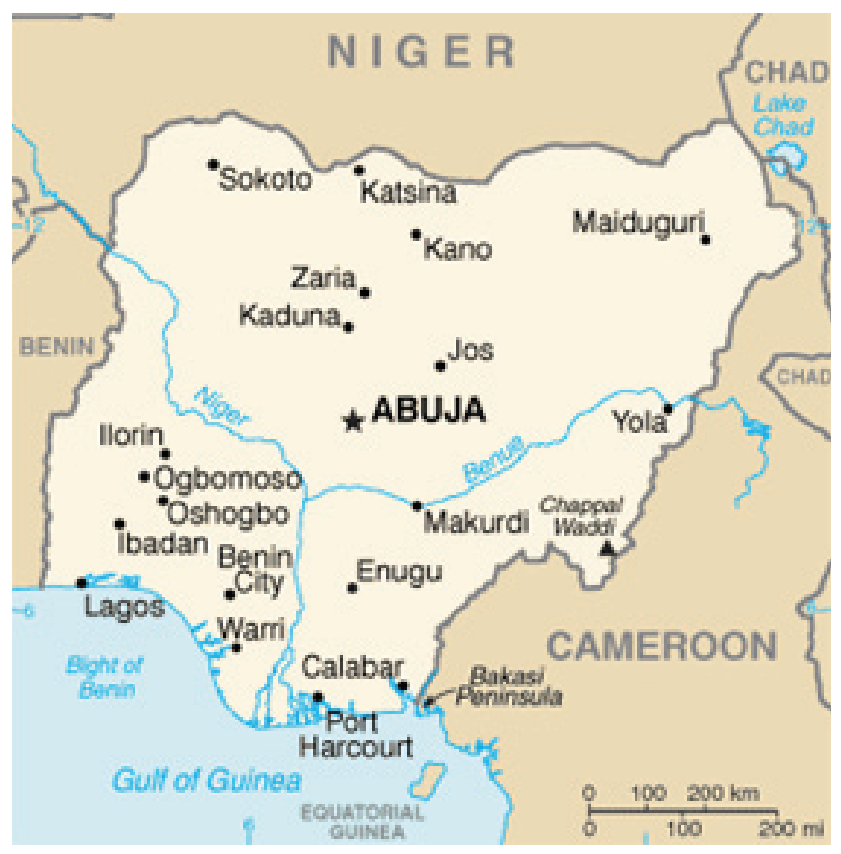

\section{DEMOGRAPHIC PROFILE}

Nigeria is the most populous country in Africa. With a population growth rate of $2.5 \%$, the population is projected to reach 433 million by the year 2050, making it the third most populous country in the world, after India and China (Population Reference Bureau 2011).

Although both maternal and infant mortality rates are very high (545/100,000 and 89/1,000 respectively), contraceptive prevalence rate (CPR) for modern

\section{DEMOGRAPHIC SNAPSHOT}

POPULATION: 162 million

PROJECTED

POPULATION IN 2050:

GROWTH RATE:

TOTAL FERTILITY RATE: (up to 7.3 in Northwest
zone)

MATERNAL

MORTALITY RATIO: INFANT

MORTALITY RATE:

BIRTHS OCCURRING

WITHIN 24 MONTHS

AFTER PRIOR BIRTH:
433 million

$2.5 \%$

5.7 children per woman

$545 / 100,000$

$89 / 1,000$

$24 \%$ 
methods has not increased significantly since 1999; $6.8 \%$ in 1999 and $9.7 \%$ presently (NPC and ICF Macro 2009). This rate is not uniform across the country-in some parts of northern Nigeria, the contraceptive prevalence rate is as low as 2.5\% (NPC and ICF Macro 2009).

\section{CHILDBEARING AND CONTRACEPTIVE BEHAVIOR}

Existing socio-cultural norms place a high value on fertility, encourage early marriage, limit women's equality, place the power to decide who receives services in the hands of the provider, and support polygamy (Izugbara and Ezeh 2010; Caldwell and Caldwell 1987). Nigeria has a high fertility rate of 5.7, with some areas in the Northwest being higher. Studies have linked the Northern region's high fertility to early marriage, of which it has one of the highest rates in the world; lack of information about and access to family planning methods; men's dominant roles as household decisionmakers; and polygyny. Polygyny encourages women to have more children than their co-wives to ensure that they will receive the largest share of the husband's resources in the event anything should happen to him (Caldwell and Caldwell 1987).

Compounding this need to have more children in order to secure greater economic and social status is the grave fear of infertility. A woman who can, or is expecting to reproduce again is regarded differently from a woman who cannot or does not want to. Even "behavioral barrenness," (Izugbara and Ezeh 2010) where one arranges or expresses the intention to no longer reproduce, has been looked down upon because of the way status is conferred upon families based on their number of children. As the Chairman of the Senate Committee on Health affirmed, "large family size ostensibly symbolizes and begets wealth, influence, respect, and fame". ${ }^{3}$ However, despite the traditional importance attached to fertility, many women do not support unregulated childbearing as they are aware of the physical risk associated with high fertility and closely spaced births, and the social and economic consequences of large families (Caldwell and Caldwell 1987).

Unfortunately, there is a pervasive misconception in Nigeria that there are many negative health implications associated with the use of modern contraceptives. A qualitative study of Northern Nigerian women's beliefs about modern contraceptives identified several negative implications of their use. Women expressed the belief that contraception causes mahaifan kulle [locked womb] and that extended use leads to a permanent loss of fertility-both serious consequences in a society where fertility is so highly valued. They also voiced concerns that modern contraceptives are injurious to women's health, possibly being laced with substances that cause cancer, result in birth defects, and lead to sexually transmitted infections (Caldwell and Caldwell 1987).

The country's health infrastructure also plays a large role in maintaining the existing level of contraceptive use. Commodity shortages, weak logistics systems, and inadequate provider knowledge and skills impede the delivery of effective family planning services. Furthermore overall funding for the health sector is low; and under health-sector reform, greater programmatic authority has been transferred to lower levels that have limited capacity. These decentralized bodies do not have the required capabilities to plan, design, and implement effective services.

\section{HEALTH SYSTEMS STRUCTURE}

The national health system is organized into a threetiered service delivery system of primary, secondary, and tertiary levels, which are the responsibility of the local, state, and federal governments, respectively. Primary care is the entry point into the healthcare system; the secondary level focuses on general and specialist care; while the tertiary level covers teaching hospitals, federal medical centers, orthopedic hospitals, and psychiatric hospitals. The structure aims to serve the needs of the population but there are numerous lapses in practice.

Each state is required to have at least one tertiary care facility, but most people access their care through the most basic primary health care (PHC) facilities. Although up to $71 \%$ of Nigerians have access to a PHC facility located within 5 kilometers of their homes, many of these service delivery centers experience frequent supply stockouts, lack proper equipment and other essential supplies, and have underqualified staff.

Due to the limitations of public health care, private facilities can assure a certain standard of quality care. However, only $30 \%$ of Nigerians visit private facilities 


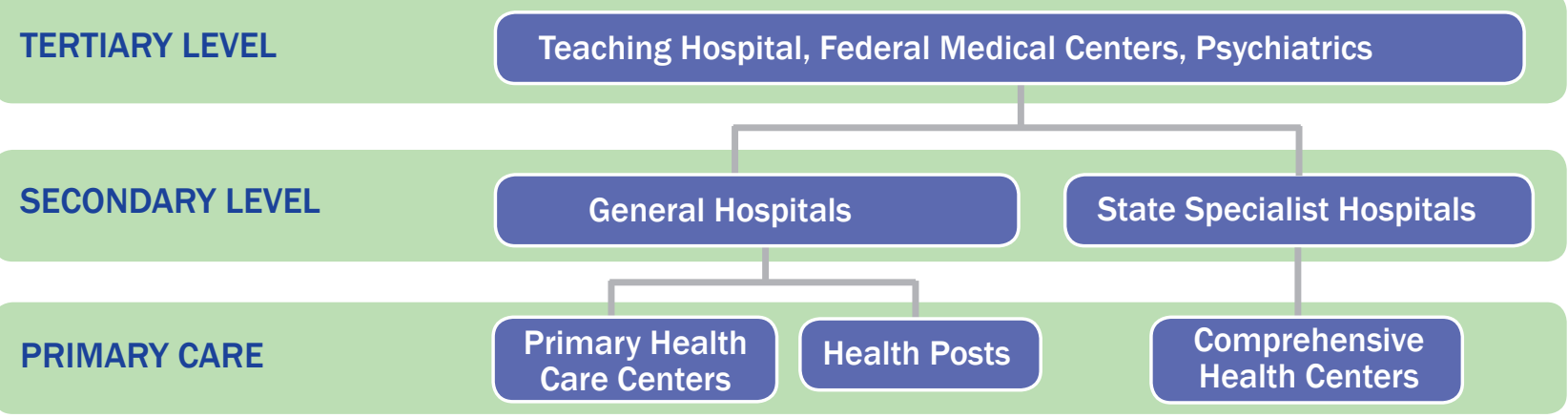

for health care services. Despite this, the private sector in Nigeria provides upwards of $60 \%$ of family planning services, and is a dominant source for delivery of contraceptive (Tien et al. 2009); nonetheless, the public sector represents a large window of opportunity for scaling up the delivery and distribution of this technology because of its capacity and proximity to more than $70 \%$ of Nigerians.

\section{FAMILY PLANNING AND REPRODUCTIVE HEALTH POLICY CONTEXT}

In response to the recognition that a high population growth rate is detrimental to national development, the government of Nigeria approved the National Policy on Population for Development in 1988. A strong family planning program was called for as an integral component of this policy. However, emerging issues such as HIV/AIDS, poverty, and gender mainstreaming programs detracted attention and funds away from the development of a federal family planning program. Progress in the areas of family planning and reproductive health stagnated, so, in 2005 , the government launched an updated version of this policy, termed the National Policy on Population for Sustainable Development.

The goal of the 2004 Revised National Health Policy was to improve the quality of life and the standard of living for the population by reducing the national population growth rate; the total fertility rate; the infant, child and maternal mortality rates; and the prevalence of HIV/AIDS, while increasing the number of females enrolled in school and the literacy rate.

The 2004 Revised National Health Policy outlines the various roles and responsibilities of the different levels of government and other organizations operating in the country to deliver or facilitate delivery of health services, including nongovernmental organizations. It also laid out programmatic strategies for ensuring a functional referral system through which people can access the appropriate care from primary, secondary, or tertiary facilities. The central government was to provide overall programmatic direction, and the state and local governments were to work with the various health-related ministries and departments at state and local levels, development agencies, and other relevant institutions to adopt and implement these policies and programs. Investments in the family planning program have not increased, challenges remain with commodity security, and the existing method mix is considered limited.

\section{Contraceptive Use and Method Mix}

Real and perceived barriers prevent many women from accessing health services, including family planning services. The NDHS 2008 report showed that poverty was the main perceived barrier to accessing health services among women (56\%), a 26 percentage point increase over the finding in the 2003 NDHS (30\%). Other disenabling factors to access care include perceived lack of drugs, transport, and distance to the health facilities (33\%), preference for a female provider (20\%), and obtaining permission to visit healthcare facilities (10\%) (NPC and ICF Macro 2009). While social and gender norms play a role in which populations utilize reproductive health and family planning services, income level does as well. Married women in the richest quintile are more likely to use a modern contraceptive (21\%) than those in the poorest quintile (4\%) (Caldwell and Caldwell 1987). This statistic highlights just one of the many barriers that keep women in Nigeria from utilizing what reproductive health and family planning services, if any, may be available to them. Consequently, and as can be 
FIGURE 2: CHART SHOWING METHODS MIX IN NIGERIA AS OF 2008

CONTRACEPTIVE METHODS USE \% (NDHS 2008)

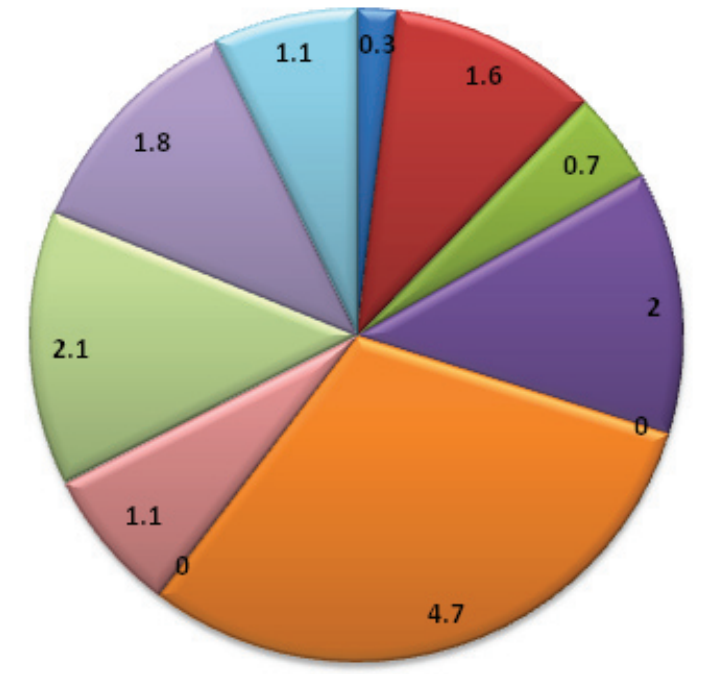

that IUCD insertion requires some level of intimate contact between the clients and providers, religious and cultural reasons in the predominantly Muslim north may play a role in the widespread aversion toward IUCDs.

Anecdotal evidence suggests that the male condom is commonly used by young unmarried people, not necessarily as a contraceptive method, but as protection against STIs. It is not particularly favored in marital relationships because of the long-held belief that it reduces sexual satisfaction and a relatively high failure seen in Figure 2 below, only 15\% of women of reproductive age use any method of contraception, $10 \%$ are using modern methods and $85 \%$ are not using any method at all (NPC and Macro ICF 2009).

Modern contraceptives available in the program include barrier methods (male and female condoms), IUCDs, combined oral contraceptive pills (Exluton and Microgynon), injectables (Depo Provera and Noristerat), implants (Implanon and Jadelle), and female sterilization, while traditional or natural methods include the lactational amenorrhea method (LAM), rhythm method, withdrawal method, and folk method.

According to the Nigeria Demographic and Health Survey (2008), 3\% of married women use injectables and $2 \%$ use pills, male condom, and LAM each, while $1 \%$ uses IUCDs. There appears to be a preference toward long- or mid-acting methods as can be inferred from the higher use of injectables (although only $3 \%$ ).

Preference for one contraceptive over another varies across the country. Married women in the South prefer IUCDs, whereas their northern counterparts prefer injectables. IUCD insertion and removal require a more sophisticated health infrastructure in terms of equipment and skilled providers, which are available more in the south. On the other hand, there is a dearth of skilled personnel in the north, and this, combined with poor health-seeking behavior, implies that northern clients may be content with other methods such as oral pills and injectables, which can be obtained at a nearby patient medical store. Furthermore, due to the fact rate in typical use. Additionally, the female condom has not enjoyed much popularity among women beyond its introductory phase. The uptake of combined oral contraceptive pills for many women is limited. The delay in return of fertility following prolonged use of injectables makes them unappealing to women in need of child spacing, due to the anxiety over such delays.

Women may overcome social, economic, and other barriers to reach a health facility but encounter additional provider and medical barriers upon reaching it. Due to the lack of skilled and trained service providers in IUCD and implant insertion and removal, especially at the lower-level facilities, these methods are often not offered. Providers too have biases and preferences for certain methods. For example, providers have been known to be judgmental and reluctant to serve single men and women, especially youths. They reflect the cultural context of widespread belief that the use of contraceptives encourages female promiscuity as it reduces the risk of consequences (unintended pregnancy).

In addition, women in Northern Nigeria seeking modern contraceptives at clinics are often asked to come in with their husbands. As some women may wish to keep their family planning intentions to themselves and prefer covert contraceptive use, this practice prevents these women from accessing services (Caldwell and Caldwell 1987).

From the foregoing discussion, it can be seen that the contraceptive environment in Nigeria is plagued by a myriad of obstacles ranging from inadequate provid- 
ers' skills to lack of adequate supply of all methods from which a prospective user can chose. Although the Population Council, as part of the International Contraceptive Access (ICA) Foundation, has been in partnership with some service-providing nongovernmental organizations, such as Pathfinder International, Rotary International, Marie Stopes, and IPPF, to increase access to the Levonorgestrel intra-uterine system (LNG IUS)-a form of IUCD-in Nigeria (part of an effort to expand method mix), and while demand for LNG IUS is steadily rising, the gap that needs to be filled is still wide. We hope that, introducing the PVR into Nigeria's program will contribute to alleviating this difficulty.

\section{Previous Experiences of Contraceptive Introduction in Nigeria}

The subdermal implant, Jadelle, was the last contraceptive method to appear in Nigeria's family planning program. It was launched as an improved version of Norplant, which was introduced in 1985 , and thus was not subject to a formal introductory process. The product was well received by policymakers, providers, and clients alike as it provided an additional long-acting noncoital dependent option with only two rods as opposed to Norplant with six rods. However, issues related to Jadelle's availability and affordability have impeded its widespread introduction. When Jadelle was introduced, it was freely distributed to stakeholders and clients, however, this was short lived. After the introductory phase, Nigerians could not afford the product at private market costs, which were around N1,000 (USD \$6)-beyond the purchasing power of ordinary Nigerians. The product is not very prevalent in the current method mix. However, as of 7 April 2011, all contraceptive commodities are free in Nigeria provided that they are accessed at a public facility. To what extent this policy is affecting supply and demand of Jadelle is yet undetermined. However, in general, continuous availability of contraceptive commodities is still an issue in Nigeria.

\section{BREASTFEEDING POLICIES AND PRACTICES}

Despite overwhelming evidence in favor of exclusive breastfeeding, only $13 \%$ of infants in Nigeria are exclusively breastfed to the age of six months (Federal Ministry of Health, 2011). Although almost all infants were breastfed (97\%), less than half of the infants (38\%) were put to breast within one hour of delivery, and only $68 \%$ commenced breastfeeding within the first day (NPC and ICF Macro 2009). At the national level, the median duration of exclusive breastfeeding is less than one month across all zones, wealth quintiles, and mother's education levels, and the median duration of predominant breastfeeding (with the addition of water and juices) is just three months. Traditionally, Nigerian women continue to breastfeed for up to two years, but the duration of both exclusive and predominant breastfeeding is shortening. According to the Nigerian Demographic and Health Survey (2008), the proportion of exclusively breastfed infants less than six months of age fell from $17 \%$ in 2003 to $13 \%$ in 2008 . The median duration of breastfeeding is 18 months though slightly longer in rural areas (19 months) in comparison to urban areas (16 months). Almost all breastfeeding children less than 6 months of age were breastfed at least six times in a 24-hour period (NPC and ICF Macro 2009). Women in the highest wealth quintile had weaned their baby completely by the age of 14 months. The median duration of postpartum amenorrhea is 11 months, although shorter in urban (8 months) than in rural areas (13 months).By as early as 8 months, $77 \%$ of mothers have resumed sexual intercourse (NPC and ICF Macro 2009). The median duration of postpartum abstinence is also very short at about 4 months with wide regional variation, 5 months in all southern regions, 2 months for the north east and north west and 7 months for north central region (NDHS, 2008).

The use of milk formula and other replacements for breast milk is on the rise among some women and HIV-positive women who have stopped breastfeeding altogether as part of the Prevention of Mother-to-Child Transmission (PMTCT) strategy. A survey conducted in 2008 revealed that only $7 \%$ of all breastfeeding children under the age of three consume infant formula (NPC and ICF Macro 2009), and a higher proportion (24\%) receives other forms of milk, mainly cow and goat. The high price of milk formula, which ranges from $\$ 6$ to $\$ 12$ per sachet, may be responsible for the low intake rates despite the rising need for such products. A majority of the population is likely unable to afford infant formula even when required, given that the proportion of the population living on less than $\$ 2$ a day is $84 \%$ (Population Reference Bureau 2010). 


\section{SECURING CONTRACEPTIVE COMMODITIES AND GETTING THEM TO MARKET}

\section{Commodity Procurement Process}

Neither the Federal Ministry of Health $(\mathrm{FMoH})$ nor its Department of Family Health is involved in direct family planning commodities procurement; all family planning commodities come from donors. Procurement of reproductive health and family planning commodities has historically never been included in the national budget. A policy breakthrough was achieved in FY2012 when FP commodities where included in the budget for the first time. It remains to be seen if this addition to the budget will result in improvements in family planning performance indicators. Many states also do not have funds dedicated to family planning and reproductive health. The system relies entirely on donations from the United Nations Population Fund (UNFPA) for public-sector family planning commodities; while the UK Department for International Development (DfID) and the United States Agency for International Development (USAID) provide private-sector support (Tien et al. 2009).

The Contraceptive Logistic Management Section (CLMS) of the FMoH works closely with UNFPA to manage, track, and distribute contraceptive commodities. Other nongovernmental organizations, such as Planned Parenthood Federation of Nigeria (PPFN) and the Association for Reproductive and Family Health (ARFH), also access and purchase public-sector contraceptives through direct request to the central level. The Requisition Issue Forms (RIFs) and Requisition, Issue, and Report Forms (RIRFs) serve as proxy mechanisms to determine the amount of supplies needed using established maximum and minimum guidelines. The country commodity manager monitors the pipeline and issues trends annually; information that is tracked centrally. States, local governments, and service delivery points order their own commodities.

Independent of which commodity is procured; distribution is done from the center to the periphery: state governments, local governments, and then service delivery points. While local governments order quarterly, the service delivery points do so every two months. However, this ordering and distribution pathway is not seamless. All government levels fail to budget for con- traception, so even donated commodities may not be transported to the needed points due to lack of funds to cover transportation costs. In 2002, the CLMS adopted the "Strategic Pathway to Reproductive Health Commodity Security" (SPARHCS) framework, a cost-recovery system to secure essential commodities for family planning and reproductive health programs. Unfortunately, issues with policy, financing, coordination, logistics, demand creation, and service delivery have prevented this SPARHCS from effecting any change, and challenges remain in ensuring a consistent supply of commodities. Due to low demand for family planning services, money recovered from sale is not enough to maintain the system; transportation costs are covered solely by the cost-recovery system and not by any government source. Thus, it is common to experience nationwide commodity stock-out despite adequate stock at the central contraceptive warehouse.

\section{Product Registration}

In Nigeria, only the manufacturer can register a product, but a waiver can be obtained. The Standard Operating Procedures (SOPs) ensure that contraceptives meet quality standards while the National Agency for Foods, Drugs Administration, and Control (NAFDAC) is the statutory body responsible for monitoring the quality of contraceptives imported into the country. Under its pharmaco-vigilence initiative, the NAFDAC is responsible for updating the safety profile of all drugs and medicine. If research needs to be conducted, the National Institute for Medical Research (NIMR) must approve and monitor the research. Once a product is cleared, the FMoH (and thus the federal government) accept the product for its intended use.

\section{SUPPORT FOR THE PVR}

\section{Perception of PVR}

The stakeholders consulted indicated that introduction of the PVR is likely to be acceptable to Nigerian society and fills a large gap in unmet family planning need. Research and input from medical professionals, politicians, senior government officials, religious and traditional leaders, and international and local nongovernmental organizations show that there is a need for a contraceptive that requires little training on the part of the provider; does not require a sophisticated health infrastructure; is very safe and long-acting and 
thus does not require monthly visits to a health center; is user-friendly and woman-controlled; and sees a quick return of fertility following discontinuation of the method. The PVR addresses all of these concerns and discussions with stakeholders indicate that it would be a welcome addition to the existing mix of contraceptive methods.

Policymakers and stakeholders in Nigeria perceive the vaginal ring innovation as a potential product to fill the contraceptive gap, especially for women in northern Nigeria, in the immediate postpartum period. Thus many stakeholders believe that the progesterone vaginal ring would be highly favored by northern clients as it is user-friendly, long-acting, does not require sophisticated health infrastructure, has a high safety profile, requires minimal facility visits, and fertility returns immediately after discontinuation of use.

In general, stakeholders in Nigeria welcome the vaginal ring and describe it as a major breakthrough in expanding contraceptive method choice. It would further empower women in the southern region to take control of their reproductive health. Moreover, it would be especially appropriate and suitable for women in the North who access healthcare facilities much less frequently, due to an aversion toward male healthcare providers, frequent need for permission from male partners to visit health facilities, poverty, and a lack of skilled personnel.

The PVR would be a welcomed method as it reduces facility visits, is user-controlled, can be inserted and removed by women themselves, and requires minimal counseling and instruction on proper use. It would also further empower women in the southern region to take charge of their reproductive lives.

Stakeholders did express some uncertainty that the ring might make intercourse uncomfortable, which could affect its popularity. However explanation, demonstration, and the testimony of satisfied clients assuaged these concerns.
Historically there have been religious-based antagonists of family planning methods in the country. They may be opposed to the PVR simply because it is a modern form of contraception. To date, no group has voiced any opposition to the PVR.

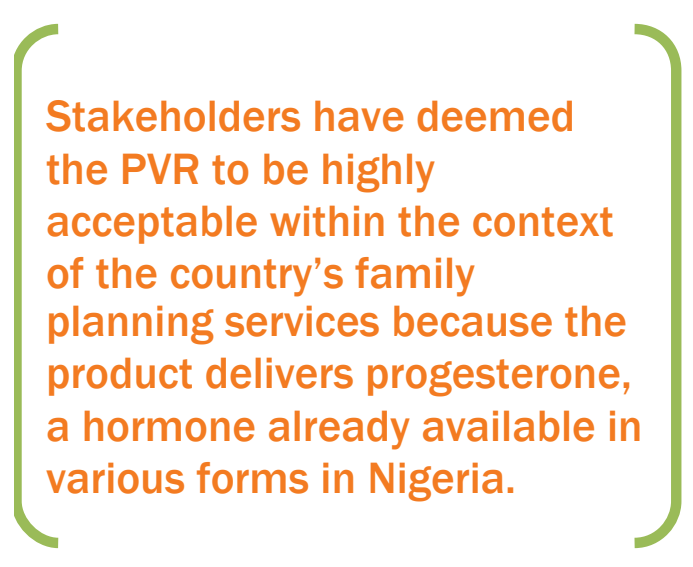

The main lesson to take away from the example of Jadelle is cost-appropriateness. At present, all family planning commodities are free in Nigeria provided that they are accessed at public facilities, but when Jadelle was first introduced they were not. Initially, when Jadelle was distributed to stakeholders and clients, it was highly popular. However, there was no arrangement in place to ensure its continuous availability at a subsidized and affordable price. Ordinary Nigerians could not afford it at private market price, thus, the initial enthusiasm abated. This experience must be considered as the PVR is being introduced in Nigeria. The design of the PVR is likely going to mitigate part of this problem. Developing a strategic plan for eventual introduction of the product is an appropriate approach.

\section{Required Resources}

Stakeholder interviews revealed key resources that were recommended to ensure successful future introduction of the PVR:

1. Competent team members

2. Local advocates

3. Good product image

4. Timely feedback

5. Local experts 


\section{DISCUSSION}

Over the past decade in Nigeria, both the contraceptive prevalence rate and the high unmet need for contraception have remained fairly static. Likewise, maternal and infant mortality rates and other reproductive health indices have not changed significantly. As stated elsewhere, multiple reinforcing factors are at fault, both individually and in concert. Lack of availability and access to longacting contraceptives, lack of skilled providers to provide implants and IUCDs, fragile health infrastructure, and limited options for postpartum family planning are prominent among the numerous obstacles to widespread use of family planning in Nigeria.

This rapid assessment of the contraceptive landscape in Nigeria has brought to light the huge demand for further expanding the contraceptive method mix, and specifically, the key role that PVR would play in this respect. For example, married women in Nigeria prefer progestogens injectables (either Depo Provera or Noristerat). These require multiple facility visits and the presence of skilled providers for administration. Some of these providers are male with whom contact is not favored by women in northern Nigeria for cultural and religious reasons. The PVR can be inserted by the woman herself with minimal coaching, obviating the need for frequent visits to health facilities, skilled service providers, and contact with male providers. The use of other postpartum family planning methods, such as Norplant and IUCDs, is also a challenge due to a lack of skilled providers. All these factors highlight the programmatic gaps that the PVR can potentially fill.

For the PVR to be fully efficacious for contraception, good breastfeeding practice is mandatory. Specifically, four breastfeeding episodes are required. Given the breastfeeding culture in Nigeria where almost all infants are breastfed (97\%), the PVR has found a friendly environment. Since only $13 \%$ of breastfeeding women exclusively breastfeed by six months, the LAM method will not suffice and effective supplementation is highly desirable, and the PVR fulfills these needs. Although eligibility cannot translate to acceptability, experience with the PVR so far has demonstrated a high level of acceptability in environments where it is intensely studied such as numerous countries in Latin America, Egypt, and India.

One global discussion that bears mentioning is the relationship between hormonal contraceptives and the risk of HIV transmission. However, such concerns were only expressed in research settings and academia, and not yet at the population and policy levels. The recent declaration by the World Health Organization advisory committee dispels this concern and recommends continuous use of hormonal methods in all client subgroups. It is worth noting that prior research has indicated an increased prevalence of vaginal infection among postpartum women in Nigeria. This acceptability study will carefully select women with vaginal infection for further management before enrollment.

One challenge that must be considered is the cost of this ring when it is finally introduced into the Nigerian market. Currently, the Nigerian government policy on family planning offers all contraceptives at public facilities free of charge provided they are available. Therefore, for the PVR to compete favorably, the unit cost must be competitive. This is one of the reasons why the federal government of Nigeria, through the Federal Ministry of Health, has been engaged in this effort from the outset. 


\section{LIST OF STAKEHOLDERS INTERVIEWED}

1. Director, Department of Family Health, Federal Ministry of Health, Federal Secretariat Complex, Abuja

2. Director, Hospital Services Department, Federal Secretariat, Federal Secretariat Complex, Abuja

3. The Chairman, Senate Committee on Health, National Assembly Complex, Abuja, Nigeria

4. Director, Center for Reproductive Health and Population, University College Hospital, Ibadan

5. Director General, National Agency for Foods, Drugs Administration, and Control, Abuja, Nigeria

6. Director General, Nigerian Institute for Medical Research, Yaba, Lagos, Nigeria

7. Director of Research and Statistics, National Population Commission of Nigeria, Abuja

8. Head, Maternal and Child Health, USAID, Murjanatu House, Abuja, Nigeria

9. The Nigerian Urban Reproductive Health Initiative, St. James' House, Wuse, Abuja

10. The President/CEO, Association of Reproductive and Family Health, Millennium Builders' Plaza, Central Business District, Abuja

11. Advocacy Nigeria/Family Planning Action Group, Lobito Crescent, Wuse 11, Abuja
12. Executive Director, Women's Health and Action Research Center, Benin City, Nigeria

13. Registrar/CEO, Pharmacists Council of Nigeria, Idu Industrial Area, Garki, Abuja

14. The Registrar, Nursing and Midwifery Council of Nigeria, Abuja

15. Executive Director, Development Communication Network, Surulere, Lagos

16. Executive Director, Center for Communication Programs-Nigeria, Maitama, Abuja

17. Federation of Muslim Women's Association of Nigeria, Maitama, Abuja

18. The President, Association of Community Pharmacist Practitioners, Abuja, Nigeria

19. Department of Obstetrics and Gynecology, University College Hospital, Ibadan

20. Medical Director, Wuse General Hospital, Abuja

21. Society for Family Health, Area 11, Garki, Abuja

22. Gender and Development Specialist, United Nation Children's Fund, UN House, Abuja 


\section{REFERENCES}

Caldwell, J.C. and P. Caldwell. 1987. "The cultural context of high fertility in sub-Saharan Africa," Population and Development Review 13(3): 409-437.

Federal Ministry of Health. Saving newborn lives in $\mathrm{Ni}$ geria: Newborn health in the context of the Integrated Maternal, Newborn and Child Health Strategy. 2nd edition. Abuja: Federal Ministry of Health, Save the Children, Jhpiego; 2011.

Izugbara, C.O. and A.C. Ezeh. 2010. "Women and high fertility in Islamic Northern Nigeria," Studies in Family Planning 41(3): 193-204.

National Population Commission (NPC) [Nigeria] and ICF Macro. 2009. Nigeria Demographic and Health Survey 2008. Abuja, Nigeria: NPC and ICF Macro.

Population Reference Bureau. 2010. http://www.prb. org/DataFinder/Geography/Data.aspx? loc=269

- 2011.

Singh, S. and J.E. Darroch. 2012. Adding It Up: Costs and Benefits of Contraceptive Services-Estimates for 2012. New York: Guttmacher Institute and United Nations Population Fund.

Tien, M. et al. 2009. Nigeria: Reproductive Health Commodity Security Situation Analysis. Arlington, VA: USAID | DELIVER PROJECT, Task Order 1. 